\title{
A Fundamental Study on the Modularization of Intelligent Skin Design
}

\author{
Jinsoo Jeong ${ }^{1}$, Ri Ryu ${ }^{2}$, Janghoo $\mathrm{Seo}^{3}$ and Yongseong Kim ${ }^{4 *}$ \\ ${ }^{1}$ Graduate School of Techno Design, Kookmin University, \\ 77 Jeongneung-ro, Seongbuk-gu, Seoul, Korea \\ ${ }^{2}$ Graduate School of Techno Design, Kookmin University, \\ 77 Jeongneung-ro, Seongbuk-gu, Seoul, Korea \\ ${ }^{3}$ Graduate School of Techno Design, Kookmin University, \\ 77 Jeongneung-ro, Seongbuk-gu, Seoul, Korea \\ ${ }^{1}$ wjdwlstn681@gmail.com, ${ }^{2}$ ri23414@hanmail.net, ${ }^{3}$ seojh@kookmin.ackr, \\ 4yongkim@kookmin.ac.kr
}

\begin{abstract}
Modern societies are paying more and more attention to energy consumption. Nations are implementing and systemizing policies on $10 \mathrm{w}$ carbon green growth to reduce greenhouse gas emission while various studies are being conducted on eco-friendly architectures and energy reducing technologies in relation to buildings. In Korea, since $39 \%$ of the total energy consumption is accounted for by buildings, the energy consumption issues of buildings have global implications that are linked to other areas such as the growing population, Centargement of buildings and technological developments. To address issues related to the energy consumption of buildings in the modern era, the importance of buitding skins has been emphasized since it has the potential to make a direct impact in terms of reducing energy, and due to the developments of IT which provides a wireless network environment, intelligent technologies such as the DOT are being widely expanded, and building skins that were once regarded as fixed exteriors are now adapting to the environment in the current era. Therefore, this study aims to examme building skins that have great potential as a high value added industy in the near future and present fundamental data on intelligent skin design and the optimized ypes that can be adopted to intelligent skin design by ascertaining the characteristics and planning factors of each category by studying a variety of cases from home and abroad.
\end{abstract}

Keywords: Intelligent skin, Surface design, Smart material, Intelligent technology, Ecological building

\section{Introduction}

\section{Background and Purpose of Study}

$1 / 3$ of the total energy consumption worldwide can be attributed to buildings and according to the data from the United States Department of Energy (DOE), 39\% of the total energy consumption of the nation is allocated to buildings [1]. Therefore, we need to devise technologies and conduct studies to achieve efficient energy reduction in the future. Also, due to many factors including the enlargement of buildings and the constructions of skyscrapers, the energy consumption of buildings has become a pressing issue. Especially, the skin of the building is where most of the energy loss occurs and the form and the composition of the skin has a significant effect on the ambience of the environment and the health of the occupants [2]. Accordingly, the importance of the 
building skin of an architecture is growing due to its direct impacts on energy reduction and the building skin is now increasingly thought of as not just a fixed exterior of a shell that surrounds an area but something that autonomously adapts to changes in the environment through intelligent technologies such as IoT with the development of IT and wireless networks. It is anticipated that intelligent skins can make a contribution to addressing global issues like reducing energy consumption.

Therefore, this study aims to research building skins that have great potential as a high value added industry in the near future and present fundamental data on intelligent skin design and the optimized types that can be adopted to intelligent skin design by learning about the characteristics and planning factors of each category by studying a range of cases from home and abroad.

\subsection{Methods and Process of Study}

This study is a fundamental study on intelligent building skins and will provide comprehensive results by defining the definitions and the spectrum of intelligent skins; the study also conducts researches on adapted technology factors and various anchitecture cases. The method of this study is shown in Figure. 1.

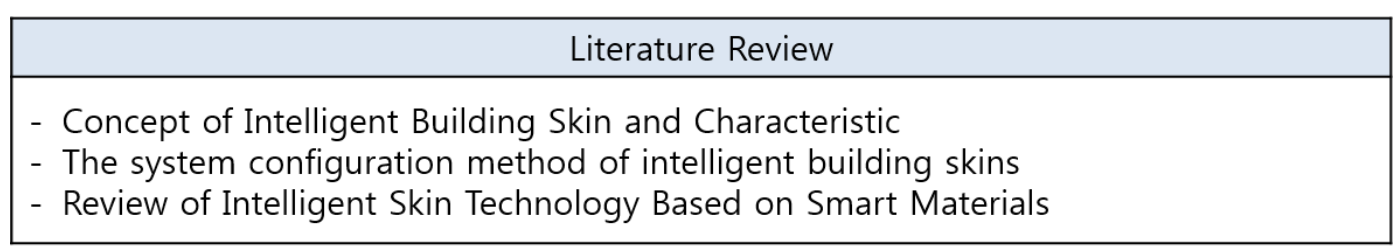
Case Study

- Case study on fundamental characteristics of the intelligent skin

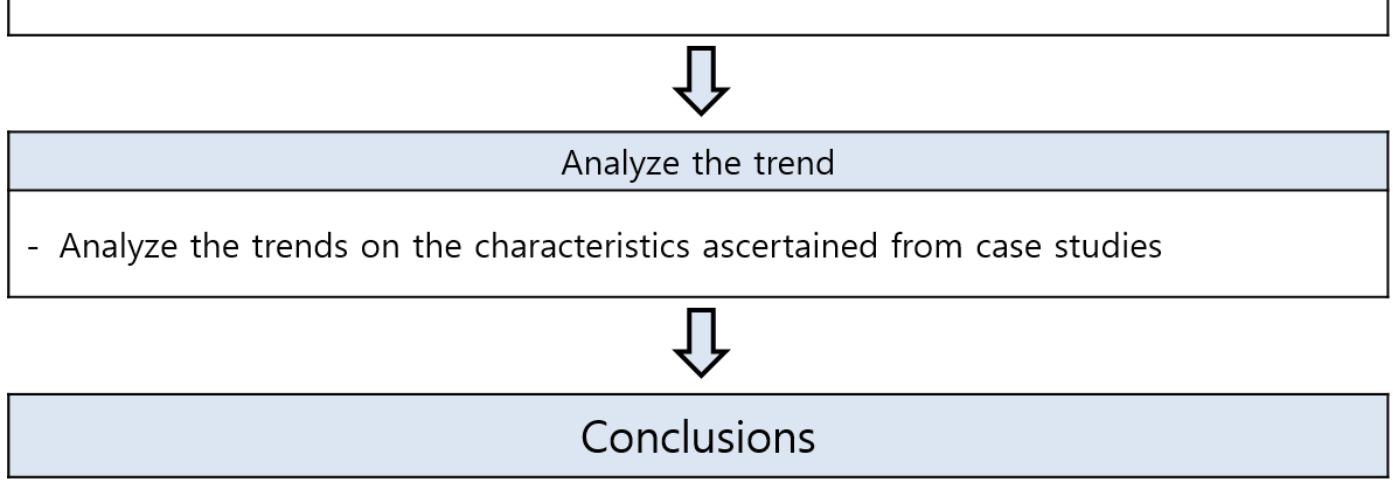

Figure 1. Study Flow Chart

\section{Theory Study of Intelligent Building Skin}

\subsection{Concept of Building Skin and Characteristic}

According to the dictionary, the building skin is a term used to describe 'the exterior of a building that surrounds the interior volume.' So the building skin is designed to react to outdoor environmental conditions and to meet artificial requirements such as safety and security. Therefore, the skin has to maintain the balance between indoor environment and the outdoor environment while protecting the inside from the outer environment. [3]. Also, the building skin is literally the skin of the building because it is composed of 
functional factors and their characteristics. In other words, the building skin is an installation that separates the interior and exterior while connecting the two [4].

\subsection{Concept of Intelligent Building Skin and Characteristic}

An intelligent building skin means the planned installation of a building skin that used to be a fixed exterior in order to mimic the intellectual abilities and the activities of a life form [5]. In addition, the intelligent building skin surrounding the interior of a building should be able to perform on the basis of its independent intelligence while controlling and managing the indoor environment such as light, heat, sound, ventilation and air conditioning through user control and the completed form of an intelligent building skin should be able to autonomously react and adjust to the changes in the external environment based on learning abilities that resemble the biological tissues of a human to maintain pleasant indoor environments and achieve energy efficiency [6]. The intelligent building skin is expected to possess differentiated effectiveness compared to existing general building skins from planning to function, design and the characteristics. The characteristics of intelligent building skins and general building skin are listed in rable. 1.

Table 1. Characteristic of Building Skin and Intelligent Building Skin

\begin{tabular}{c|c|c}
\multirow{2}{*}{ Plan } & Building skin & Intelligent building skin \\
\cline { 2 - 3 } Function & Architecture specialists & Cooperation with diverse engineers \\
\hline Design & manual control & $\begin{array}{c}\text { dynamic skin reacting to } \\
\text { environmental changes }\end{array}$ \\
\hline Advantages & fixed skin & $\begin{array}{c}\text { High initial cost, but eventually } \\
\text { reduces costs due to reduction of } \\
\text { environmental burden and energy } \\
\text { consumption }\end{array}$ \\
\hline
\end{tabular}

\subsection{The System Configuration Method of Intelligent Building Skins}

The intelligent building Skm system is composed of sensor, operator, and controller. The sensor senses the environmental information and converts it into a notable signal and sends it to the controller. The operator deduces the most effective adaptation method among diverse vartables. Finally, the controller performs the physical operation and prudent reaction and responds to the environment by following the command ascertained from the operator. Figure. 2 is the operating method of the intelligent building skin.

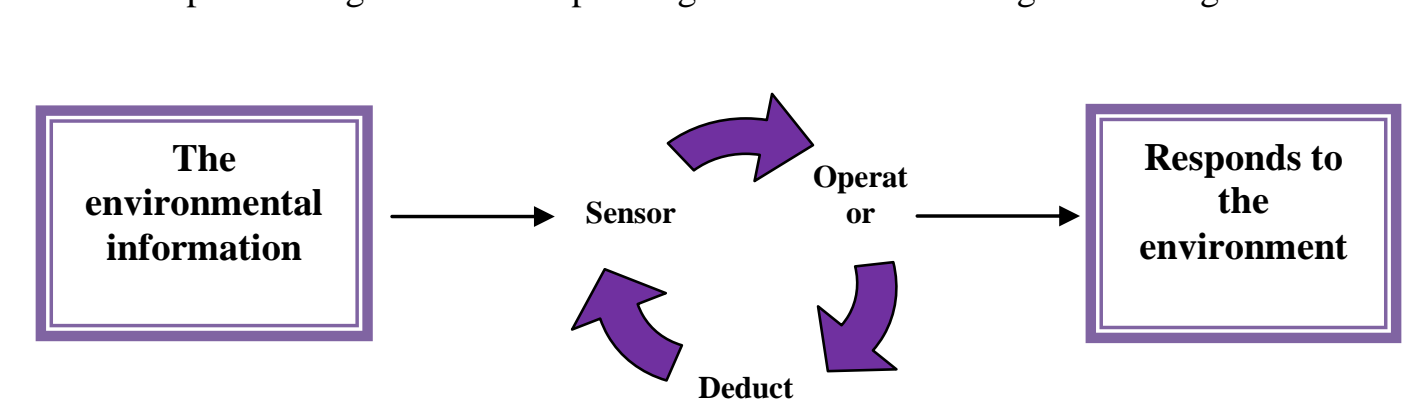

Figure 2. The Operating Method of the Intelligent Building Skin 


\subsection{Review of Intelligent Skin Technology based on Smart Materials}

The smart material is a new material concept that responds to the surrounding environment like a living creature that is different from existing materials that need to be manually operated. A smart material has been reprocessed to react with high sensitivity to a specific stimulus so it can be significantly utilized to realize intelligent building skins with its remarkable reactivity without any help from specific software or additional installation [7]. The intellectual ability of a smart material depends on its ability to change its characteristics according to diverse conditions and flow of time, and the smart material could undergo multiple changes in its characteristics according to its performance [8]. It was adapted in the medical sector in its early stages and recently, it has been adapted in architectures, which implies that the concept of intelligent architecture is being generalized.

The function of a smart-material-based intelligent building skin is determined by the characteristics of the smart material so its ability to respond to diverse environments is lower than that of computer systemized intelligent building skin utilizing sensors, operators and controllers. However, the smart materials have great potential with regard to the intelligent building skin industry because its growth potential is boundless, and it requires simple design routes with relatively low cost, and due to the fact it is highly compatible with computers [5].

Table 2. A smart Material Applied to Intelligent Building Skin

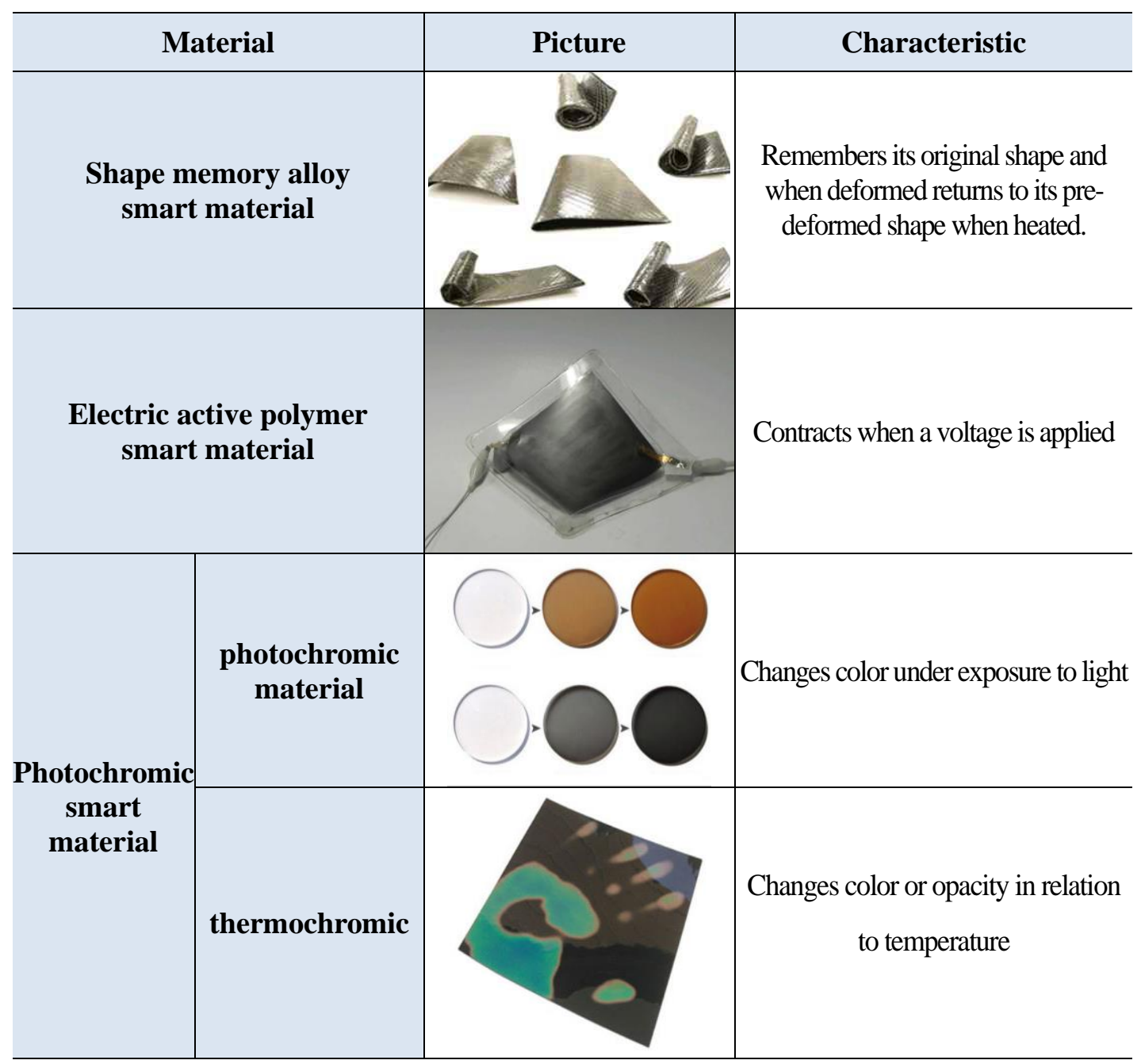




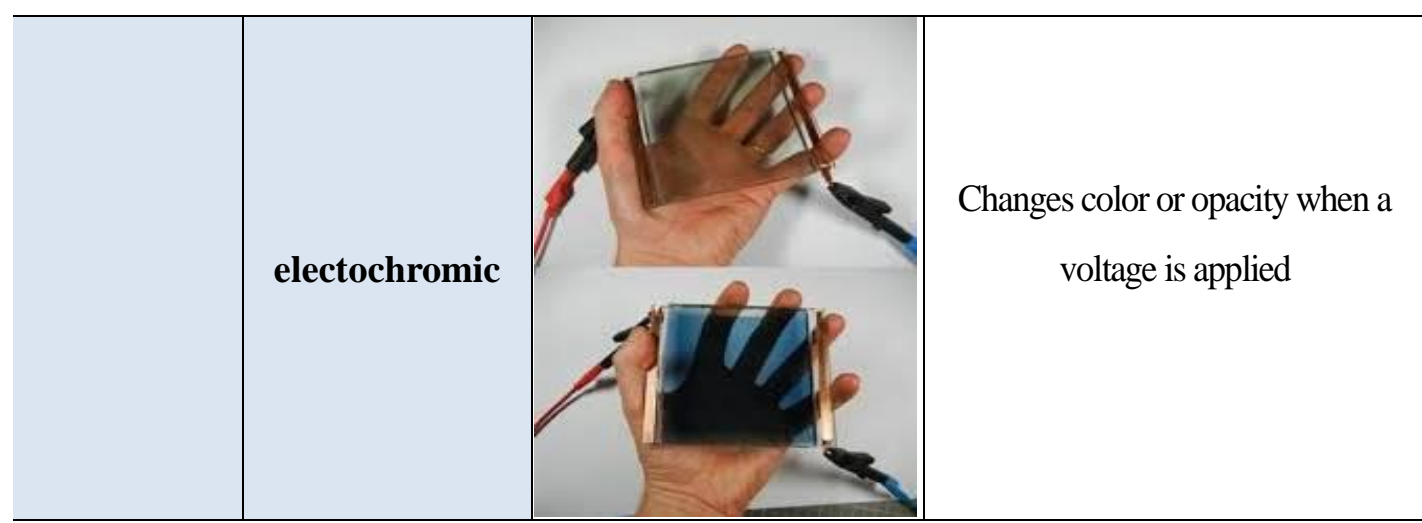

A smart material changes under diverse stimulus and can be categorized under the types of stimulus and it is divided into materials that change under natural conditions and artificial stimulus as shown in Table. 2. A representative example of a smart material that changes under natural conditions is the shape-memory alloy which is an al oy that "remembers" its original shape and when deformed returns to its pre-deformed shape when heated. A piezoelectric material is a smart material that changes ander artificial stimulus. A piezoelectric material contracts when a voltage is applied. And chromogenic systems change color in response to electrical, optical or thermal changes. The value of these types of smart materials will increase since they can be utilized in the intelligent building skin field.

\section{Intelligent Skin of Case Studies}

The analysis of intelligent skin case shows the method of displaying intelligence with respect to the responsiveness, variation, and usefulness, which are the basic properties of an intelligent building skin. Table 3 shows the methods of displaying intelligence analyzed from the cases of intelligent skins.

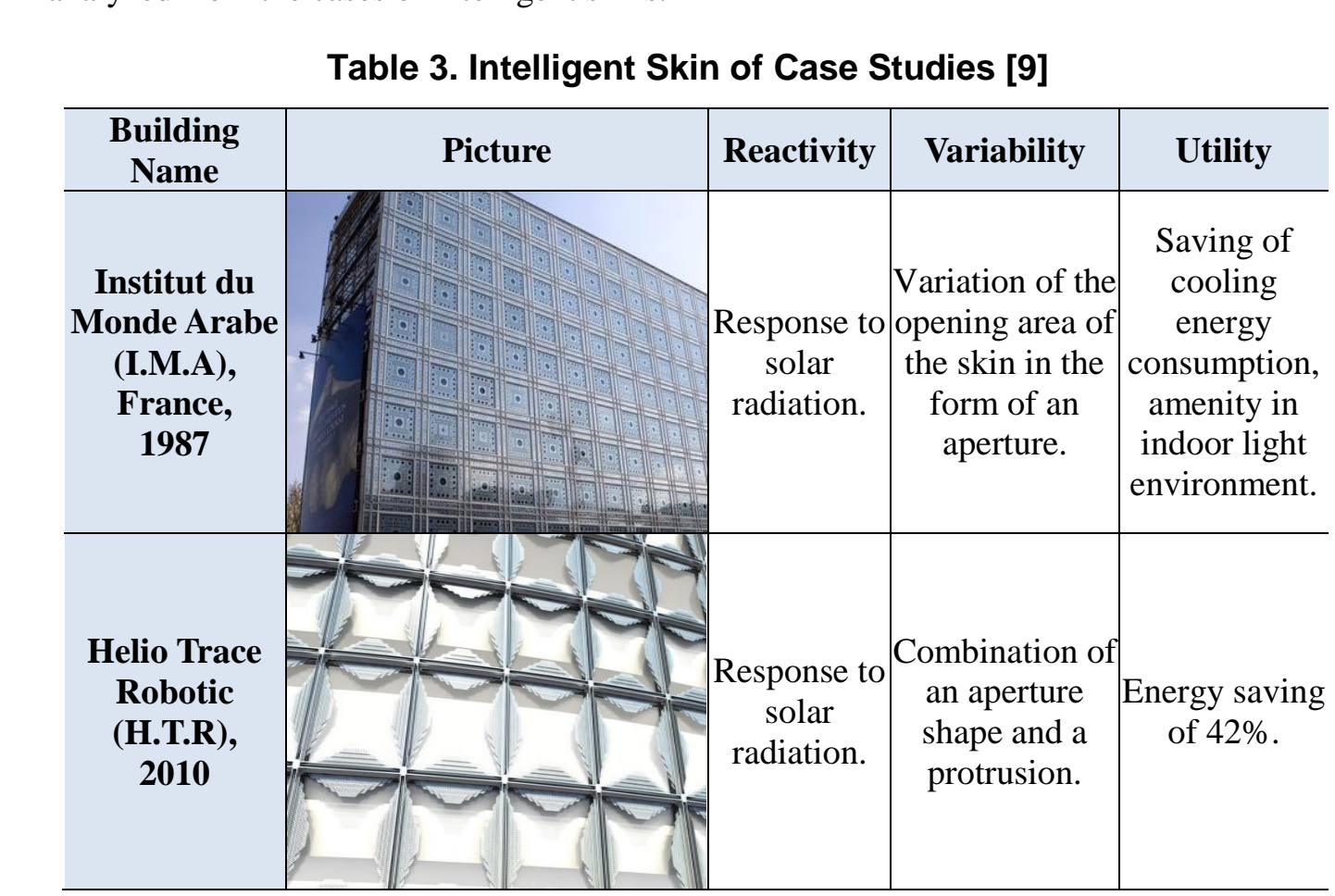




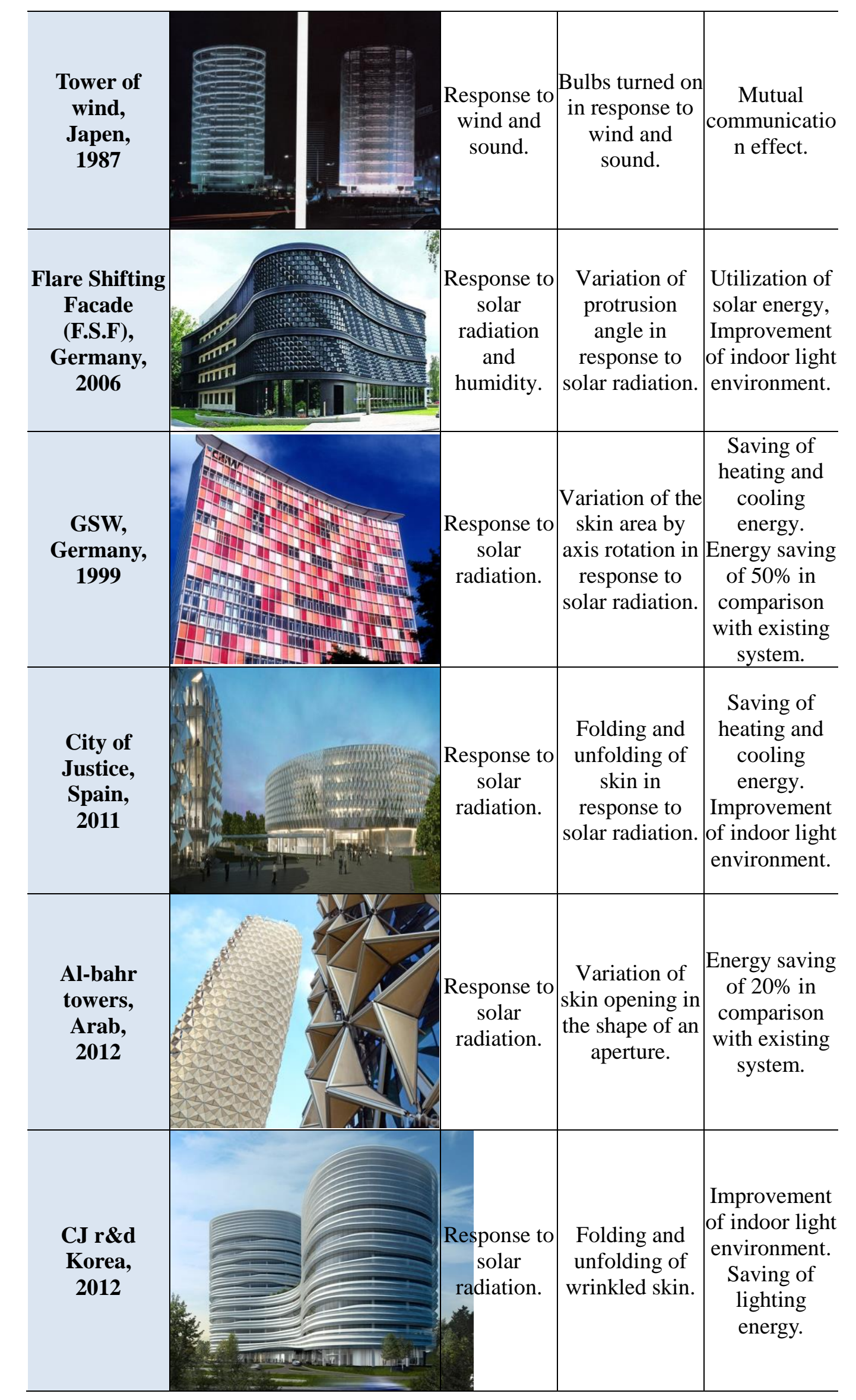




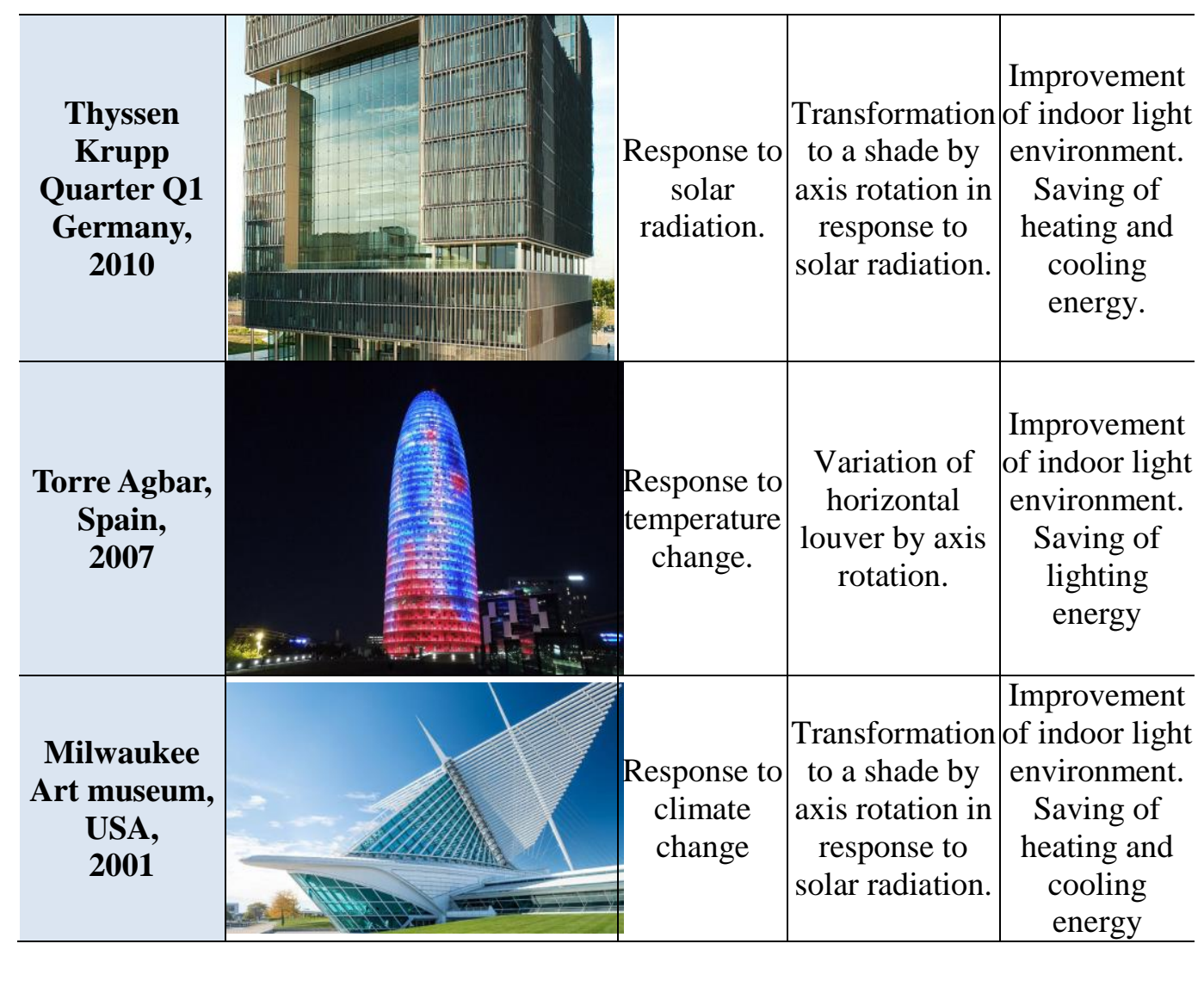

The changes of the skin depend on the formation of the subject and the system. For example, the skins that have reactivity to sunrays will respond to exterior stimulus that will create changes in the form of apertures of rotational positions. These changes will induce the diverse variability of the building skin and also affect the indoor environment.

Through the analysis of intelligênt building skin cases we will deduce an analysis standard in types of intelligent bulding skin and observe trends by analyzing the distribution of such intelligent building skins through the evaluation table.

Table 4.Trend Analysis of Intelligent Skin

\begin{tabular}{|c|c|c|c|c|c|}
\hline \multirow{3}{*}{$\begin{array}{c}\text { Building } \\
\text { Name }\end{array}$} & \multicolumn{5}{|c|}{ Reactivity } \\
\hline & \multicolumn{2}{|c|}{ Reacting type } & \multicolumn{3}{|c|}{ Sensor recognition } \\
\hline & $\begin{array}{l}\text { Physical } \\
\text { reaction }\end{array}$ & $\begin{array}{c}\text { Chemical } \\
\text { reaction }\end{array}$ & Sun & Temperature & etc. \\
\hline (MA) & 0 & & 0 & & \\
\hline HTR & ○ & & 0 & & \\
\hline $\begin{array}{c}\text { Tower of } \\
\text { Wind }\end{array}$ & 0 & & & & 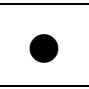 \\
\hline FSF & 0 & & 0 & & 0 \\
\hline GSW & ○ & & 0 & & \\
\hline $\begin{array}{l}\text { City of } \\
\text { Justice }\end{array}$ & 0 & & 0 & & \\
\hline $\begin{array}{l}\text { Al-bahr } \\
\text { tower }\end{array}$ & 0 & & ○ & & \\
\hline
\end{tabular}




\begin{tabular}{|c|c|c|c|c|c|}
\hline $\begin{array}{l}\text { Cj R\&D } \\
\text { Center }\end{array}$ & 0 & & 0 & & \\
\hline $\begin{array}{l}\text { Thyssen } \\
\text { Krupp } \\
\text { Quarter Q1 }\end{array}$ & ○ & & ○ & & \\
\hline Torre Agbar & ○ & & 0 & & \\
\hline $\begin{array}{l}\text { Milwaukee } \\
\text { Art museum }\end{array}$ & 0 & & & & ○ \\
\hline \multirow{3}{*}{ Name } & \multicolumn{5}{|c|}{ Variability } \\
\hline & \multirow{2}{*}{$\begin{array}{c}\text { Rotational } \\
\text { position }\end{array}$} & \multirow{2}{*}{\multicolumn{3}{|c|}{\begin{tabular}{l|r}
\multicolumn{2}{|c}{ Contraction/expansion } \\
Sliding & Apertures \\
\end{tabular}}} & None \\
\hline & & & & & etc. \\
\hline IMA & & & 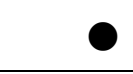 & & \\
\hline \multicolumn{6}{|l|}{ HTR } \\
\hline \multicolumn{6}{|l|}{$\begin{array}{c}\text { Tower of } \\
\text { Wind }\end{array}$} \\
\hline \multicolumn{6}{|l|}{ FSF } \\
\hline GSW & 0 & & & & \\
\hline \multicolumn{6}{|l|}{$\begin{array}{l}\text { City of } \\
\text { Justice }\end{array}$} \\
\hline \multicolumn{6}{|l|}{$\begin{array}{c}\text { Al-bahr } \\
\text { tower }\end{array}$} \\
\hline \multicolumn{6}{|l|}{$\begin{array}{l}\text { Cj R\&D } \\
\text { Center }\end{array}$} \\
\hline \multicolumn{6}{|l|}{$\begin{array}{c}\text { Thyssen } \\
\text { Krupp } \\
\text { Quarter Q1 }\end{array}$} \\
\hline \multicolumn{6}{|l|}{ Torre Agbar } \\
\hline \multicolumn{6}{|l|}{$\begin{array}{l}\text { Milwaukee } \\
\text { Art museum }\end{array}$} \\
\hline \multirow{3}{*}{ Name } & \multicolumn{5}{|c|}{ Utility } \\
\hline & \multicolumn{2}{|c|}{ Indoor environment } & \multicolumn{3}{|c|}{ Reduce energy } \\
\hline & Light Feat & Air condition & Light & Cooling & Renewable \\
\hline IMA & 0 & & & 0 & \\
\hline HTR & 0 & & & 0 & \\
\hline $\begin{array}{c}\text { Tower of } \\
\text { Wind }\end{array}$ & & & & & \\
\hline ESP & 0 & 0 & & & 0 \\
\hline GSW & 0 & & & 0 & \\
\hline $\begin{array}{l}\text { City of } \\
\text { Justice }\end{array}$ & ○ & & & ○ & \\
\hline $\begin{array}{l}\text { Al-bahr } \\
\text { tower }\end{array}$ & 0 & & & ○ & \\
\hline $\begin{array}{l}\text { Cj R\&D } \\
\text { Center }\end{array}$ & $\bullet$ & & & ○ & \\
\hline $\begin{array}{c}\text { Thyssen } \\
\text { Krupp } \\
\text { Quarter Q1 }\end{array}$ & 0 & & 0 & 0 & \\
\hline
\end{tabular}




\begin{tabular}{c|c|c|c|c|c|c}
\hline Torre Agbar & $\bullet$ & $\bullet$ & & $\bullet$ & $\bullet$ & \\
\hline $\begin{array}{c}\text { Milwaukee } \\
\text { Art museum }\end{array}$ & $\bullet$ & $\bullet$ & & & $\bullet$ & \\
\hline
\end{tabular}

As shown in Table .4, most physical reactions due to sunrays are in regard to reactivity and apertures in variability, indoor environment, light and heating conditions and reduction of cooling energy, so we can conclude that since the purpose of intelligent building skin is to reduce indoor energy consumption by adapting to the outdoor environment as a composition factor of intelligent building skins, many of them were designed for environments that have great effects on indoor energy consumption such as light, heating, and reduction of cooling energy.

\section{Conclusions}

There is increasing interest about energy consumption in the moder era which automatically leads to greater interest in $\mathrm{CO}_{2}$ emission. Among forms of energy consumption, $39 \%$ of energy consumption is attributable to buldings. Therefore, we need to devise technologies and conduct studies to effectively address the mater of reducing energy consumption. The building skin is responsible for most of the energy loss and its formation and composition is responsible for energy reduction and the pleasantness of the indoor environment. Therefore, the importance of the building skin will be increasingly recognized in the future. Also the development of IT and wireless networks, intelligent technologies such as IOT is expanding ând bullding skins that were once merely thought of as a fixed exterior are now regarded@s intelligent and able to adapt and respond to the environment. It is anticipated that the intelligent building skins will make a great contribution to maintaining pleâsan conditions indoors and reducing energy consumption unlike current building skins.

Therefore, we conducted a case analysis and examined the trends of intelligent building skins by reviewing preceding studies and the result of this study shows that sunrays induced the greatest hysical reaction in terms of reactivity and the most changes in formation occurred in apertures in terms of variability, and in terms of utility, its purpose being to improve light and heating conditions while reducing cooling energy consumption. Therefore, we can conclude that the trend of intelligent building skins is to effectively control the amount of sunlight with awning technology and improve indoor light and heating conditions and the chief goal is to reduce cooling energy consumption.

In upcoming studies that utilize this study as fundamental data regarding intelligent building skin design module to realize intelligent building skins, we must review the validity of the proposal and the system of intelligent building skins designed to control light as outhined in the case studies presented in this study.

\section{References}

The Proceedings of the Korean Institute of Illuminating and Electrical Installation Engineers 24(6), 2010.11) pp55-62.

[2] S.B. Lee, "Building envelope design for energy saving", Korean Institute of Architectural Sustainable Environment and Building Systems Journal of Korea, Vol.1, No.2, (2007), p27.

[3] W.D. Seo, "A Study on the Expressional Characteristics and the Application of Intelligent Skin Design in Environment-Friendly Architecture.”, Journal of Korea, (2006).

[4] Christian Schittich, "Building Skins, Birkhauser", (2001), p29.

[5] K.H. Choi, "A Fundamental Study on Planning of Intelligent Skins Module”, Journal of Korea, (2014), p8.

[6] Michael Wigginton \& Jude Harris, Intelligent Skins, Elservier, (2003), p23.

[7] J.H. Park, J.R. Park: "Cross section and Sight of Contemporary Architecture", Spacetime, (2013), p278.

[8] T. Schropfer: "Material design”, Springer Verlag, (2013), p23. 
[9] J.S. Jeong, R. Ryu, J.H. Seo, Y.S. Kim, "Fundamental Study on Intelligent Skin Design", Asia-pacific Proceedings of Applied Science and Engineering for Better Human Life, Vol.2, (2016), pp. 42-45

[10] The Magazine of the Society of Air-Conditioning and Refrigerating Engineers of Korea, (2012), pp66-74.

[11] S.A. Kim: "Digital Architecture and BIM", Review of Architecture and Building Science, (2012), pp1518.

[12] G.H. Koh, J.G. Kim: "Study of the structure of the skin for the management measures energy efficient buildings.", Architectural Institute of Korea, (2014), pp93-94.

\section{Authors}
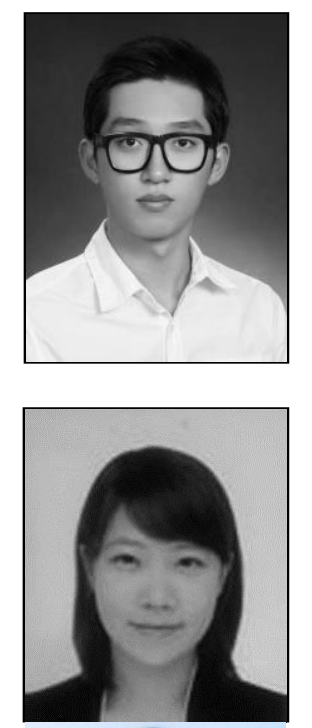

\section{Ri Ryu}

\section{Jinsoo Jeong}

Master Course, Graduate School of Techno Design Kookmin

University, 77 Jeongneung-ro, Seongbuk-gu, Seoul, Korea

E-mail : wjdwlstn681@naver.com

Doctor candidate, Graduate School of Techno Design Kookmin

University, 77 Jeongneung-ro, Seongbuk-gu, Seoul, Korea

E-mail : ri123414@hanmail.net

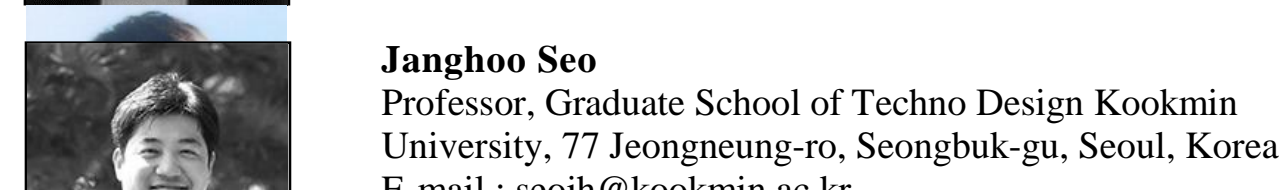

E-mail : seojh@kookmin.ac.kr

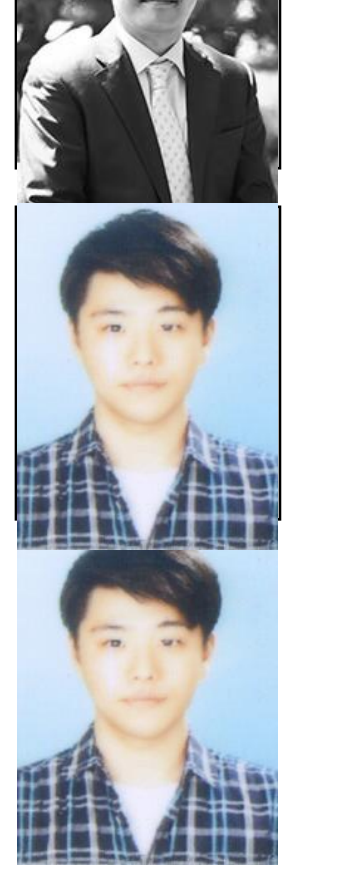

\section{Yongseong Kim(Corresponding author)}

Provessor, Graduate School of Techno Design Kookmin

University, 77 Jeongneung-ro, Seongbuk-gu, Seoul, Korea

E-mail : yongkim@kookmin.ac.kr 